\title{
CAPABILITIES, LIMITATIONS AND OPPORTUNITIES FOR STUDYING SINKHOLES USING SYNTHETIC APERTURE RADAR INTERFEROMETRY
}

\section{Cathleen E. Jones}

Jet Propulsion Laboratory, California Institute of Technology, 4800 Oak Grove Dr., Pasadena, CA 91109 USA, cathleen.e.jones@jpl.nasa.gov

\begin{abstract}
We give an overview of past work using synthetic aperture radar (SAR) interferometry (InSAR) to detect, observe and characterize sinkholes, present the advantages and disadvantages of using satellite-borne SARs for this application, and discuss the availability to the community of free and open SAR data. In particular, we discuss the planned NASA-ISRO Synthetic Aperture Radar (NISAR) mission, a joint venture between the National Aeronautics and Space Administration (NASA) and the Indian Space Research Organisation (ISRO) currently being built for launch in 2022 .
\end{abstract}

\section{Introduction}

Because of the prevalence of rock susceptible to dissolution, natural sinkholes can be found on all the continents except Antarctica (Ford and Williams, 2013). In fact, it is estimated that up to $40 \%$ of the contiguous US is susceptible (Weary and Doctor, 2014) and the at-risk area is even larger when cavity collapse in general, including that unrelated to dissolution of rocks, is considered (e.g., collapse of mines, pipes, and lava tubes). The spatial scale alone of the area to be covered makes groundbased monitoring difficult, encouraging the application of remote sensing methods to sinkhole location and assessment. Indeed, one can argue that even many groundbased methods are 'remote' in that they seek to identify underground caverns from the surface. However, here we consider a different scale of operation and take up the topics of how well sinkholes can be identified and studied from space and what instruments are available to use for the purpose.

No Earth-observing spaceborne instruments currently exist that can identify subterranean caverns directly, so all sensors detect ground surface conditions that could be indicative of a sinkhole, and rely on ancillary data and in situ measurements for validation. Sinkhole mapping and change tracking using remote sensing methods can be done based on several identifying features, all of which are also used in field surveys.
Historically topographic survey methods have been used most commonly to identify areas of subsidence, with surface elevation, change in elevation, and shape of the depression as the primary sinkhole indicators. These remain the most commonly used sinkhole indicators accessible with remote sensing. Soil moisture, standing water and vegetation type, particularly that which is different from the surrounding area, are secondary indicators also measurable to some extent with remote sensing. Additionally, because sinkholes form where rainwater or snowmelt percolates through the soil, their presence can sometimes be inferred from the water flow pathways, particularly from changes in the presence or absence of standing water without an apparent surface run-off path (e.g., Hofierka et al., 2018).

Although several remote sensing instruments are available (radar, lidar (Light Detection and Ranging), and optical/infrared imagers), lidar is now the most frequently used remote sensing technique for sinkhole identification. Unfortunately, no existing spaceborne lidar has the needed resolution for this purpose. A future lidar-based land surface topography mission with ground spacing of 1-m to 5-m was identified as a high priority in the 2017 Decadal Survey undertaken by the National Academy of Sciences but was acknowledged to be not yet technically feasible (NAS, 2018). This leaves radar as the most promising candidate for measuring the topographic indicators of sinkholes from space. Today there are a number of spaceborne synthetic aperture radars (SARs) with spatial resolution sufficient to be of use for some of the larger sinkholes, at least, and more are planned for the future, including a NASA Earth observing SAR mission scheduled for launch in 2022. These instruments and their suitability are the topics of the following sections.

\section{SAR Applied to Sinkhole Study Overview}

SAR imaging instruments available in the civilian sector in general are not able to achieve the decimeter spatial resolution of optical imagery. The finest available SAR 
spatial resolution of order $0.5-\mathrm{m}$ and more typical values are in the range of 10 to $20-\mathrm{m}$. The advantage of SAR over optical and infrared imagers is its potential for measuring surface elevation and surface deformation through interferometry, or InSAR (Massonnet, 1997).

There are two types of InSAR, one that uses the data from two SARs simultaneously imaging the surface but from offset positions, called single-pass InSAR, and often referred to as radar altimetry because it is used for topographic mapping, i.e., measuring surface elevation. The other form of InSAR, known as differential InSAR (DInSAR), measures surface deformation, i.e., change in surface position over time, and uses one SAR instrument imaging the surface at different times to measure the change in line-of-sight distance to the ground. Figure 1 shows pictorially how DInSAR works by relating the change in phase of the backscattered signal to a change in the distance between the radar antenna and the scattering surface. In the literature, the term InSAR is often used in reference to differential interferometry, but we choose to use the term DInSAR herein to differentiate it from single-pass InSAR.

Both single and repeat pass InSAR (herein called InSAR and DInSAR, respectively) are of value to sinkhole studies. The two subsections below provide a short review of the type of sinkhole research and results to date.

\section{Repeat-pass InSAR (Differential InSAR or DInSAR)}

DInSAR is specifically sensitive to changes in the surface, so it is useful for identifying actively deforming landscapes. Sinkholes can be identified using DInSAR because it highlights the shape of the deforming areas combined with subsidence relative to the surrounding terrain. Because it measures deformation, DInSAR cannot map inactive sinkholes or sinkholes that show no or very slow surface subsidence.

Research has shown that some actively deforming sinkholes can be identified using DInSAR. In particular, it has been used to identify areas experiencing ground movement indicative of sinkhole initiation and progression (Conway and Cook, 2013; Jones and Blom, 2015; Shi et al., 2019), measure surface deformation velocity and acceleration (Kim et al., 2019), measure precursory ground movement before catastrophic collapse (Nof et al., 2013; Jones and Blom, 2014) and identify likely locations for catastrophic collapse sinkhole formation (Atzori et al., 2015; Baer at al., 2018).

\section{Single-pass InSAR (Radar Altimetry or InSAR)}

InSAR is used for topographic mapping much like lidar and leveling surveys, and in the same way can be used to identify terrain with either active or inactive sinkhole activity through elevation contrast and the shape of depressions.

DInSAR has been used more for sinkhole studies than InSAR, and this is mainly because there is only one instrument, TanDEM-X operated by the German Space Agency, that is capable of high spatial resolution topographic mapping. In addition, TanDEM-X data and derived products are available through a commercial provider (not free and open). The commercially available digital elevation model (DEM) derived from TanDEM-X images, WorldDEM, is generated with a horizontal resolution of 12-m, although the underlying imagery used has higher spatial resolution (5-m). The WorldDEM has a root mean square height error of $1.1-\mathrm{m}$ in low vegetation and 1.8-m in forests (Wessel et al., 2018), making it useful only for studying large sinkholes. To date, no sinkhole study based on WorldDEM has been reported. However, one study of TanDEM-X's utility for sinkhole

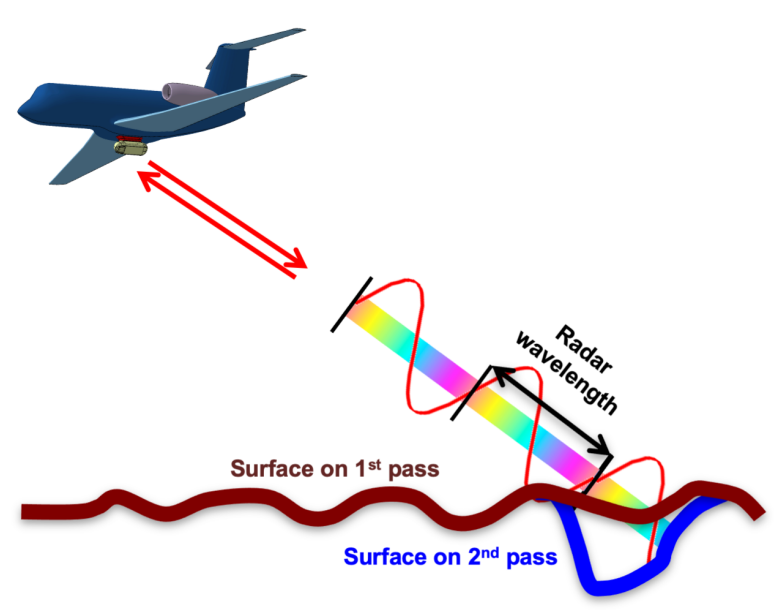

Figure 1. Schematic of DInSAR

Differential, or repeat pass, SAR interferometry (DInSAR) works by measuring the phase change between the return pulses from a surface imaged at two different times from the same orbit and location. If the surface was displaced during the interval between when the images are acquired, then there is a change in the phase of the backscattered signal. One radar wavelength corresponds to $4 \pi$ radian phase change in the two-way path length along the line-of-sight direction. [Derived from (Jones, 2016)] 
studies has been published, in which the authors generated a higher resolution DEM from TanDEM-X imagery (Vajedian and Motagh, 2019). In that study, sinkholes of diameter $\sim 20$-m to 40-m were identified with accuracy of $\sim 1-\mathrm{m}$ in both depth and diameter.

\section{Pros and Cons of Spaceborne SAR for Sinkhole Study}

Spaceborne imaging has a number of advantages over ground-based monitoring methods, the most obvious being wide spatial coverage in a single image, reliable and regular repeated imaging, consistent measurement methodology independent of location, and seamless imaging of areas not easily accessed by ground. Satellite-based instruments provide the combination of large spatial coverage and regular temporal repeat needed for sustained regional surveying. Depending upon the data access policy, e.g., NASA's sensors' data are free of charge, satellite remote sensing can be very cost-effective. SARs, which operate in the microwave portion of the electromagnetic spectrum, have the additional advantage of being able to image through clouds and not needing solar illumination of the surface since they emit pulses and receive the backscattered signals ('active' instruments).

The efficacy of sinkhole detection with any particular instrument depends upon its spatial resolution, measurement accuracy, and the ability to penetrate vegetation to measure the properties of the ground. The first two can vary with the mode of operation for a single instrument; the last depends upon the operating frequency of the SAR: The ability to penetrate vegetation scales with the frequency of the radar, with higher frequency (shorter wavelength) instruments less able to penetrate vegetation than lower frequency (longer wavelength). Typical wavelengths are $3.3 \mathrm{~cm}$ (X-band missions TerraSAR-X/ TanDEM-X, COSMO-SkyMed), $5.5 \mathrm{~cm}$ (C-band missions Sentinel-1, Radarsat-2, Radarsat Constellation Mission) and $23.8 \mathrm{~cm}$ (L-band missions ALOS-2, SAUCOM). The choice of frequency is quite important for sinkhole studies, particularly in areas where vegetation and soil moisture vary significantly over time (e.g., seasonally or with the precipitation/drying cycle) as is often the case in sinkhole-prone areas.

Typically, measurements of ground deformation using DInSAR can achieve accuracies of order a centimeter for a single pair of images, and ground deformation rates with accuracy in the millimeters per year range are achievable given a sufficiently long times series of acquisitions for which phase coherence is maintained. Loss of phase coherence due to temporal decorrelation is caused by activities that disrupt the surface (e.g., plowing), and can be reduced by increasing the frequency of acquisitions (shorter time between acquisitions). For DInSAR, images must be acquired sufficiently often for the surface to not decorrelate between imaging (Zebker and Villasenor, 1992). However, spaceborne instruments have fixed repeat-orbit intervals, usually in the 1-to-3-week range. Constellations of identical instruments can achieve shorter repeat intervals using images from several instruments, but currently the maximum number of instruments in a SAR constellation is four (for COSMO-Skymed), and Sentinel-1 uses two instruments to achieve a 6-day repeat interval.

Decorrelation is less severe for longer wavelength radars, so L-band is preferred for sinkhole studies in areas where decorrelation is a problem. Most DInSAR-based sinkhole studies to date have been done in arid environments where temporal decorrelation is not an issue (e.g., Dead Sea sinkholes and the west Texas Wink Sinks). However, the measurement of precursory deformation associated with the Bayou Corne sinkhole used L-band and obtained a good measurement across a 1-year time interval (Jones and Blom, 2014). The sinkhole was caused by collapse of a mined cavern within a salt dome in southern Louisiana. The setting in that case was one with dense vegetation and high soil moisture, so precursory movement detection is an encouraging outcome for those interested in studying sinkholes with DInSAR in areas like Florida with similar SAR imaging challenges.

Geological hazards that result in large scale surface deformation like earthquake fault ruptures and volcanic dome expansion have been long studied with DInSAR, but sinkholes provide additional challenges for spaceborne imaging not present for those studies. Sinkholes come in a wide range of sinkhole sizes $(<1-\mathrm{m}$ to $>100$ $\mathrm{m})$ and the smaller ones cannot be resolved reliably. To have confidence in identification, a cluster of pixels must show consistent movement so, e.g., an instrument with 20-m resolution is unlikely to be useful for identifying sinkholes of size $<100-\mathrm{m}$. The small size of the features can also be an advantage however, because identifying sinkholes only requires that the sinkhole show subsidence relative to the surrounding ground and DInSAR's relative accuracy is much higher than its absolute accuracy and does not require tie points to a geodetic frame (e.g., GNSS stations within the imaged area). 
In areas where sinkhole collapse occurs rapidly, i.e., over weeks to months, frequent updates to the survey are needed for identifying active sinkholes based on surface displacement. Obviously, precursory movement cannot be detected for sinkholes that progress from the state of no surface indication to collapse more rapidly than the SAR imaging interval (orbit repeat interval).

A major source of error for DInSAR is noise introduced by changes in temperature, pressure, and water vapor in the troposphere (Doin et al., 2009) and total electron content in the ionosphere (Gray et al., 2000). However, these artifacts vary on the scale of kilometers or larger so they have less impact on sinkhole detection. To the extent that atmospheric noise is random, its affect is reduced through the use of many different acquisitions processed as a time series (a 'stack') (Bekaert et al., 2015).

The utility of single-pass InSAR for sinkhole studies is largely driven by the combination of spatial resolution and height accuracy of the DEM derivable from the data. Future improvements in DEM resolution and accuracy will directly impact the utility of single-pass InSAR for sinkhole mapping. However, updates to a global DEM will not be made often (usually it is several years at least before a DEM is updated) so DInSAR remains the best option for identifying new and active sinkholes and monitoring their development from space.

Neither DInSAR or InSAR can replace measurements made from the ground, with the most notable disadvantages being (1) spatial resolutions of 1-m at best and 10-20-m for the most abundant currently available data, that provided by the European Space Agency's (ESA's) Sentinel-1 mission; (2) no on-demand data acquisitions because a satellite must be in position to image the site and orbits typically repeat at days-to-weeks intervals; (3) the need for specialized processing to obtain deformation information for which many users are untrained; and (4) the cost of the data and the processing. However, it is an effective tool in identifying likely sinkhole sites and for monitoring of the larger active sinkholes.

There are a number of online sites freely offering information on InSAR and tools/training for processing. Interested readers could use the Alaska Satellite Facility's Webinar and Tutorial website as a starting point (https:// earthdata.nasa.gov/learn/user-resources/webinars-andtutorials). The SAR cost disadvantage is less significant than it was in the past because ESA currently offers the Sentinel-1 data open source and free of charge. The Sentinel-1 mission can achieve 6-day repeat interval, however not all land areas are acquired on every pass and, although most land areas are eventually imaged, there is no formal commitment to do so and in practice the 6-day repeat imaging occurs for few locations outside Europe. The situation will change in the near future because NASA will launch its own satellite SAR mission, NISAR (for NASA-ISRO SAR), and offer the data open source and free of charge. With that in mind, the NISAR mission and its suitability for sinkhole studies are described below.

\section{NISAR: The NASA-ISRO SAR Mission}

The NISAR mission is being developed through a partnership between NASA and ISRO to provide a set of instruments and observations of broad utility for science and applications. The mission will collect data in support of ecosystem, cryosphere and solid earth sciences. The acquisition plan is designed for studying dynamic processes that occur at the week-to-year timescale and the mission will provide global measurements suitable for determining the causes and consequences of land surface changes through Earth system modeling. The mission does not have any requirements for sinkhole science specifically, but given the technical capabilities of the instrument, the data acquired will be useful for that purpose. The mission and its utility for sinkhole studies are described below.

\section{NISAR Instrument and Mission Description}

The NISAR satellite will carry two SAR instruments, both designed for InSAR, one operating at L-band provided by NASA (L-SAR) and the other operating in the S-band (10-cm wavelength) provided by ISRO (S-SAR). The mission is scheduled to launch from Satish Dwawan Space Center in Sriharikota, India, on an ISRO Mark II launch vehicle during the period January-May 2022. The L-SAR and S-SAR mission components are designed for a minimum lifetime of 3 years and 5 years, respectively but on-board propellant supports a longer mission so operations are likely to extend if the instruments remain in operating condition.

Unlike many satellite SAR instruments, NISAR is designed to provide simultaneously both high spatial resolution and a wide imaging swath using a new technology, SweepSAR (Freeman et al., 2009). The L-SAR image 


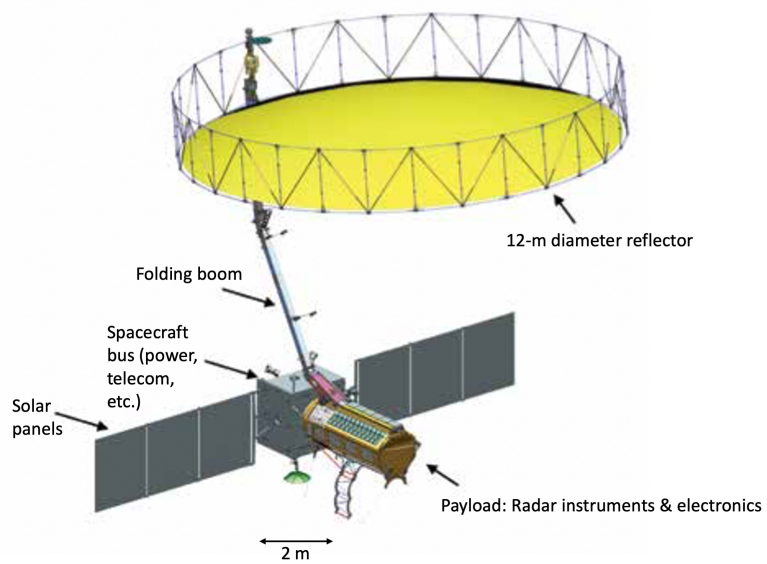

Figure 2. Schematic of the NISAR Satellite NISAR uses a 12-m diameter antenna reflector and the transmit/receive SweepSAR technology to obtain a 240-km wide image swath independent of the spatial resolution. The current operational plan is to acquire 6-m $\times$ 7-m spatial resolution data over North America and 12-m $\times 7-m$ data over much of the rest of the globe's land areas.

swath is $240-\mathrm{km}$ wide, independent of spatial resolution. The wide image swath enables the mission to achieve a 12-day repeat orbit cycle with global coverage capability. The orbit repeat cycle is determined by the number of orbits needed to cover the globe with a non-overlapping $240-\mathrm{km}$ swath width at the equator. A single orbit takes 100 minutes to complete.

The L-band instrument will acquire data over almost all land surfaces and sea ice between latitudes $87.5^{\circ} \mathrm{S}$ and $77.5^{\circ} \mathrm{N}$. For land, the L-band instrument's spatial resolution is planned to be $6-\mathrm{m} \times 7-\mathrm{m}$ in North America and $12-\mathrm{m} \times 7-\mathrm{m}$ elsewhere. The S-band instrument will mainly acquire data over India and targets in its national interest, however the L-band and S-band radars are designed to operate alone or together. The mission will acquire and downlink approximately 35 Tbits/day of data for the L-band instrument alone, and an additional estimated 8-9 Tbits/day for the S-band instrument. For normal processing, products will be generated and released within 48 hours of acquisition. Although the NISAR mission is focused on Earth science, the mission system is designed to provide rapidly processed products, within 5 hours of acquisition, when tasked for disaster response. More information is available online on the NISAR applications, science, technology and operations in NISAR Science Users' Handbook (NISAR, 2018).
An Assessment of NISAR's Sinkhole Study Capability

NISAR will provide several significant improvements over other available SAR missions that can benefit sinkhole study specifically. We focus on the L-band SAR because it is to collect data over nearly all land globally. We mainly compare to Sentinel-1 because that instrument has the nearest comparable coverage and its data are free and open to all, as are the data from all NASA Earth Observing missions, including NISAR. This is a crucial factor in making SAR remote sensing accessible to many who could not otherwise afford to use it.

First, the L-band radar is better suited to imaging below vegetation and will maintain higher coherence. Because the repeat interval is 12 days, this means that excellent long-term ground motion monitoring will be possible in areas where slow subsidence cannot be well monitored with other instruments. The spatial resolution is well-matched to observing sinkholes and it is reasonable to expect that surface features as small as $30-\mathrm{m}$ in diameter could be identified in some areas where 6-m spatial resolution imagery is acquired. There are plans in review for the NISAR project to provide atmospheric corrections as standard layers in the DInSAR products, which means that many SAR users will not have to implement or purchase specialized processing to remove those artifacts from the data. The combination of reliable imaging and open data access is key to enabling operational sinkhole hazard monitoring, and the global scope of the data set will allow this type of capability to be implemented on a region-specific basis.

The NISAR Science Team in association with NASA Headquarters has undertaken a number of activities to engage the end user community in advance of NISAR's launch to further the use of the mission's data by engineers and decision makers. The activities and white papers describing other practical applications of SAR are available on the NISAR Applications website (https:// nisar.jpl.nasa.gov/applications/).

\section{Acknowledgements}

This work is carried out at the Jet Propulsion Laboratory, California Institute of Technology, under contract with the National Aeronautics and Space Administration (NASA). 


\section{References}

Atzori S, Baer G, Antonioli S. 2015. InSAR-based modeling and analysis of sinkholes along the Dead Sea coastline Geophysical Research Letters 42: 8383-8390.

Baer G, Magen Y, Nof R, Raz E, Lyakhovsky V, Shalev E. 2018. InSAR measurements and viscoelastic modeling of sinkhole precursory subsidence: Implications for sinkhole formation, early warning, and sediment properties. Journal of Geophysical Research: Earth Surface 123: 678-693.

Bekaert D, Walters R, Wright T, Hooper A, Parker D. 2015. Statistical comparison of InSAR tropospheric correction techniques. Remote Sensing of Environment 170: 40-47.

Conway BD, Cook JP. 2013. Monitoring evaporite karst active subsidence in the Holbrook Basin, Arizona using interferometric synthetic aperture radar (InSAR). In: Land L, Doctor D, Stephenson JB, editors. Proceedings of the 13th Multidisciplinary Conference on Sinkholes and the Engineering and Environmental Impacts of Karst; 2013 May 6-10; Carlsbad, New Mexico. Carlsbad (NM): National Cave and Karst Research Institute. p. 187-194.

Doin M, Lasserre C, Peltzer G, Cavalie O Doubre C. 2009. Corrections of stratified tropospheric delays in SAR interferometry: validation with global atmospheric models. Journal of Applied Geophysics 69: 35-50.

Ford D, Williams P. 2013. Karst Hydrogeology and Geomorphology. Hoboken (NJ): John Whiley \& Sons. 562 p.

Freeman A, Krieger G, Rosen P, Younis M, Johnson WTK et al. 2009. SweepSAR: Beam-forming on receive using a reflector-phased array feed combination for spaceborne SAR. In: Proceedings of the 2009 IEEE Radar Conference; 2009 May 4-8; IEEE. https://doi.org/10.1109/ RADAR.2009.4977140.

Gray AL, Mattar KE, Sofko G. 2000. Influence of ionospheric electron density fluctuations on satellite radar interferometry. Geophysical Research Letters 27: 1451-1454.
Hofierka J, Gallay M, Bandura P, Sasak J. 2018. Identification of karst sinkholes in a forested karst landscape using airborne laser scanning data and water flow analysis. Geomorphology 308 : 265-277.

Jones CE, Blom RG. 2014. Bayou Corne, Louisiana, sinkhole: Precursory deformation measured by radar interferometry. Geology 42: 111-114.

Jones CE, Blom RG. 2015. Pre-event and postformation ground movement associated with the Bayou Corne sinkhole. In: Land L, Doctor D, editors. Sinkholes and the Engineering and Environmental Impacts of Karst: Proceedings of the 14th Multidisciplinary Conference; 2015 Oct. 5-7; Rochester, Minnesota. Carlsbad (NM): National Cave and Karst Research Institute. p. 415-422.

Jones CE. 2016. A practical guide to synthetic aperture radar for engineering and environmental geologists. In: Anderson RL, Ferriz H editors. Applied Geology in California, Association of Environmental and Engineering Geologists Special Publication 26; Redwood City (CA): Star Publishing Company. p. 567-584.

Kim JW, Lu Z, Kaufmann J. 2019. Evolution of sinkholes over Wink, Texas, observed by highresolution optical and SAR imagery. Remote Sensing of Environment 222: 119-132.

Massonnet D. 1997. Satellite radar interferometry. Scientific American 276: 46-53.

NISAR. 2018. NASA-ISRO SAR (NISAR) Mission Science Users' Handbook. Pasadena (CA): NASA Jet Propulsion Laboratory. 261 p. [Cited 2019 Oct 18] Available from: https://nisar.jpl.nasa.gov/files/ nisar/NISAR\%20FINAL\%209-6-19.pdf.

National Academies of Sciences, Engineering, Medicine (NAS). 2018. Thriving on Our Changing Planet: A Decadal Strategy for Earth Observation from Space. Washington (DC): The National Academies Press. 694 p.

Nof R, Baer G, Ziv A, Eval Y, Raz E, Atzori S, Salvi S. 2013. Sinkhole precursors along the Dead Sea, Israel, revealed by SAR interferometry. Geology 41: 1019-1022. 
Paine JG, Buckley SM, Collins EW, Wilson CR. 2012.

Assessing collapse risk in evaporate sinkhole prone areas using microgravimetry and radar interferometry. Journal of Environmental \& Engineering Geophysics 17: 75-87.

Shi Y, Tang Y, Lu Z, Kim J-W, Peng J. 2019.

Subsidence of sinkholes in Wink, Texas from 2007 to 2011 detected by time-series InSAR analysis. Geomatics, Natural Hazards and Risk 10: $1125-1138$.

Vajedia S, Motagh M. 2019. Extracting sinkhole features from time-series of TerraSAR-X/ TanDEM-X data. ISPRS Journal of Photogrammetry and Remote Sensing 150 : 274-284.

Weary DJ, Doctor DH. 2014. Karst in the United States: a digital map compilation and database. US Geological Survey Open File Report 2014-1156. $23 \mathrm{p}$.

Wessel B, Huber M, Wohlfart C, Marschalk U, Kosmann D, Roth A. 2018. Accuracy assessment of the global TanDEM-X digital elevation model using GPS data. ISPRS Journal of Photogrammetry and Remote Sensing 139: 171-182.

Zebker H, Villasenor J. 1992. Decorrelation in interferometric radar echoes. IEEE Transactions on Geoscience and Remote Sensing 30: 950-959. 